\title{
A (IN)DISPONIBILIDADE DO INTERESSE PÚBLICO NA UTILIZAÇÃO DA
}

\author{
ARBITRAGEM
}

\author{
Rodrigo Crepaldi Perez Capucelli ${ }^{1}$ \\ Rubens Beçak ${ }^{2}$
}

\begin{abstract}
RESUMO: O presente artigo destaca os limitantes que baseiam o princípio da indisponibilidade do direito público como fatores preponderantes para a definição do campo de utilização da arbitragem para a resolução de conflitos surgidos no âmbito da administração pública. Para tanto, buscou-se traçar uma breve análise do próprio princípio da indisponibilidade aplicado ao direito público e de seus fundamentos, e então contextualizá-lo à luz da Constituição Federal de 1988, para que então fosse feita a análise das limitantes da aplicação do instituto da arbitragem, considerando especialmente suas recentes modificações dadas pela Lei 13.129/2015.
\end{abstract}

Palavras-chave: Arbitragem; Indisponibilidade do Interesse Público; Direito Administrativo; Constituição Federal de 1988; Nova Administração Pública.

\section{THE (UN)AVAILABILITY OF PUBLIC INTEREST IN THE USE OF}

\section{ARBITRATION}

\begin{abstract}
This article aims to analyze the limitations that are based on the Government's strict abidance by the public interest as preponderant factors for the definition of the field of use of arbitration for the resolution of conflicts in the public administration. For this purpose, a brief analysis was made of the principle of unavailability applied to public law and its foundations, and from then on to contextualize it in the light of the Federal Constitution of 1988, so that the analysis of the limitations of the application of the arbitration institute, especially considering its recent modifications provided by Law 13.129/2015.
\end{abstract}

Keywords: Arbitration; Unavailability of Public Law; Administrative Law, Federal Constitution of 1988; New Public Management.

\footnotetext{
${ }^{1}$ Mestre em Direito Constitucional pela Faculdade de Direito de Ribeirão Preto da Universidade de São Paulo (USP).

${ }^{2}$ Mestre e Doutor em Direito Constitucional e Livre-docente em Teoria Geral do Estado pela Universidade de São Paulo - USP. Professor Associado da Universidade de São Paulo - USP - Secretário Geral da Universidade de São Paulo (2010-14). Professor Visitante na Universidad de Salamanca no Centro de Estudios Brasileños.
} 


\section{INTRODUÇÃO}

Desde a Constituição Imperial podemos encontrar exemplos do uso da arbitragem para a solução de conflitos envolvendo o interesse público no Brasil, mas foi a partir do final do século passado que o seu uso se solidificou, principalmente em razão da promulgação da Lei 9.307/96, momento que coincide com um projeto mais amplo de diminuição da máquina pública e sua descentralização idealizada pelo pensamento neoliberal e concretizada pelas reformas administrativas iniciadas na década de 1990.

Historicamente a administração pública brasileira pode ser dividida em três grandes modelos - patrimonialista, burocrática e gerencial - e, embora sempre coexistentes, cada um é, nesta ordem, predominante a partir do período republicano até os dias atuais, mas as bases principiologicas constitucionais que às sustentam sempre estiveram sobre prismas semelhantes. Assim, embora notória a tentativa do legislador em fortalecer mecanismos extrajudiciais de solução de litígios, sua utilização no âmbito da administração pública tem aspectos controvertidos os tanto academicamente quanto jurisprudencialmente, principalmente quando os debates partem da contraposição dos princípios da supremacia e da indisponibilidade do direito público, eis que teoricamente impediriam - ou ao menos limitariam - o uso da ferramenta pela administração pública.

Neste sentido, apesar da existência de tentativas legislativas pontuais que permitissem a aplicação da arbitragem como forma de resolução e conflitos na atividade pública, tais demandas incidiram de forma significativa a partir da publicação da recente Lei 13.129/15 que trouxe de forma expressa a autorização para a utilização da arbitragem pela administração pública. A ampliação albergada pela lei, para alguns, traduz-se em uma evolução no Direito Administrativo resultando em maior celeridade e eficácia na composição de seu s conflitos, considerando que será realizada por meio de juízos técnicos, compostos por árbitros escolhidos pelas partes e em menor tempo do que uma demanda judicial. Mas, mesmo com a previsão legal, muitas discussões sobre os limites da arbitragem na administração pública ainda se mantêm, e, na prática, a sua aplicabilidade ainda não fora colocada em prova. 


\section{A (IN)DISPONIBILIDADE DO INTERESSE PÚBLICO}

Ao atribuir ao povo todo poder mas condicioná-lo ao exercício por meios de seus representantes $^{3}$ a Constituição Federal de 1988 estrutura a sociedade a partir de um sistema democrático representativo baseado no mandato, dissociando a titularidade do poder de decisão: enquanto a primeira pertence ao povo, resta à administração - em seu sentido amplo - tomar e executar as decisões públicas da melhor forma que atenda o interesse público.

Executor da vontade pública, o Estado encontra o desafio de proteger o interesse público e assim, mesmo que haja um necessário aparato burocrático administrativo para se dar concretude às decisões públicas - pois a administração estatal não deve ter um fim em si mesma -, deve propiciar o melhor benefício possível ao real titular do poder, o povo.

Conceituar "interesse público" é uma árdua tarefa, principalmente em razão de sua amplitude. Muitas vezes para uma definição mais didática um dos caminhos é contrapô-lo com o interesse particular, como, por exemplo, podemos extrair das palavras de Maria Sylvia Zanella Di Pietro (2017, p. 136):

[...] as normas de direito público, embora protejam reflexamente o interesse individual, tem o objetivo primordial de atender ao interesse público, ao bemestar coletivo. Além disso, pode-se dizer que o direito público somente começou a se desenvolver quando, depois de superados o primado do Direito Civil (que durou muitos séculos) e o individualismo que tomou conta dos vários setores da ciência, inclusive a do Direito, substituiu-se a ideia do homem com fim único do direito (própria do individualismo) pelo princípio que hoje serve de fundamento para todo o direito público e que vincula a Administração em todas as suas decisões: o de que os interesses públicos tem supremacia sobre os individuais [...]

A administração pública atua limitadamente, e não pode dispor livremente daquilo que não lhe pertence. Se é o povo o titular do poder e seu principal destinatário, ao delegar a gestão e a alocação de recursos e direitos não perde sua titularidade pois o representante (seja ele em âmbito político ou administrativo) estará imerso em uma limitação de decidir, ainda que indiretamente, em prol do povo. Para José dos Santos Carvalho Filho (2014, p. 36) o princípio da indisponibilidade é que enfatiza tal situação, e assim os bens e interesses públicos não pertencem à administração nem a seus agentes, cabendo-lhe apenas a gestão.

\footnotetext{
${ }^{3}$ Recorte do Art. $1^{\circ}$. Parágrafo Único da Constituição Federal de 1988, constante no título relativo aos Princípios Fundamentais da República Democrática Brasileira.
}

Rev. de Formas Consensuais de Solução De Conflitos | e-ISSN: 2525-9679 | Porto Alegre | v. 4 | n. 2 | p. 28 - 48 | Jul/Dez. 2018 
Essa vinculação da administração pública ao interesse público como fundamento para suas próprias decisões proíbe ao representante agir em prol de interesses que sejam particulares ou de um grupo, quando destoam da vontade geral dos representados. Para tanto, protege-se as decisões da administração pública com uma série de princípios, dentre eles a "indisponibilidade" do interesse público, que deve todo ato administrativo deve levar em consideração.

Muito embora a centralização do poder da tomada de decisões públicas basear-se em fundamentos garantistas em prol da sociedade, observamos nas últimas décadas que o aparato Estatal rígido e maçante pode obstar as suas próprias finalidades. Se na esfera política a representação tem encontrado cada vez mais ferramentas baseadas na participação direta como forma de complementar a democracia, afim de se construir o que alguns autores chamam de democracia semidireta ${ }^{4}$, na esfera administrativa ferramentas de participação e de accountability com o cidadão estão cada vez mais orientando a formulação dos atos administrativos.

Destacamos duas importantes formas de empoderamento da sociedade civil a partir de suas causas: a primeira desponta do esgotamento da representação como única forma de participação política, que encontra saídas nas ferramentas participativas diretas como a criação de conselhos populares, de audiências públicas, de experiências de participação popular em elaboração de orçamentos públicos, etc.; e a segunda baseia-se na insustentabilidade da centralização das atividades do Estado frente às novas demandas da administração pública. Em ambas, é notória a extensão do poder-dever da administração pública à terceiros que não foram eleitos pelo clássico sistema "legitimador" do voto, ou seja, a preocupação com a disponibilidade do interesse público parece envolver uma crescente parcela da sociedade.

Na perspectiva econômica, com o declínio da Guerra Fria e a derrotada do ideal socialista, o avanço do pensamento neoliberal impôs aos estados modernos uma gestão pública mais eficiente, pulverizada e descentralizada. As novas formas de organizações sociais moldaram uma necessidade de se rever o papel do Estado e consequentemente impuseram à gestão pública o desenvolvimento de novos modelos que refletiram na forma pelo qual o interesse público pode ser defendido, e em razão dele as decisões sejam tomadas.

\footnotetext{
${ }^{4}$ À título de exemplificação, Norberto Bobbio em seu livro Estado, Governo e Sociedade (1987, p.459) define democracia semidireta como uma forma de democracia que possibilita um sistema mais bem-sucedido de democracia frente às democracias representativa e direta, ao permitir um equilíbrio operacional entre a representação política e a soberania popular direta.
} 
Atualmente, a dicotomia público/privado tem sucumbido às instituições e organizações que ocupam espaços cujas competências transitam entre àquilo que afeta a liberdade do indivíduo e a necessidade da sociedade. O aumento da complexidade das relações jurídico-econômicas e a necessidade de se estruturar um aparato estatal que seja capaz de garantir os direitos sociais que a Constituição de 1988 lhe incumbiu trouxeram uma nova necessidade de se aprofundar a análise de toda atuação em nome daquilo que entendemos como interesse público.

\section{A NOVA ADMINISTRAÇÃO PÚBLICA E A CONSTITUIÇÃO FEDERAL DE 1988}

A abordagem gerencial da administração pública defende a introdução de conceitos e ideias da administração privada no setor público fundamentando-se na teoria do neoliberalismo econômico, tornando-se o movimento teórico propulsor da chamada Reforma da Administração Pública brasileira estruturada em 1994, no governo de Fernando Henrique Cardoso.

A reforma administrativa brasileira na década de 1990 pode-se dizer influenciada por atores econômicos mundiais, principalmente o Fundo Monetário Internacional (FMI) e o Banco Interamericano de Desenvolvimento (BID), através de imposições de condições para manutenção de empréstimos à países da América Latina, assim como pelas recomendações do Consenso de Washington (1989) fundamentadas na ideias econômicas ${ }^{5}$ de John Williamson (PAULA, 2014, p. 112-113).

Para PAULA (2014, p.114-115) é possível identificar duas vertentes na reforma dos anos 1990: a vertente gerencial e a vertente societal. A primeira se alinha ao movimento internacional de reforma de Estado e a segunda herda as ideias de movimentos contra a ditadura e em prol da redemocratização. Quanto à segunda vertente, há um importante aspecto que deve ser destacado: a reforma dos anos 1990 é peculiar às demais reformas pelas quais o Estado brasileiro já havia passado em outras épocas ${ }^{6}$ justamente porque incluía a dimensão sociopolítica - que se refere à participação dos cidadãos nas decisões de natureza pública - no debate.

\footnotetext{
${ }^{5}$ Segundo PAULA (2014, p. 113) o economista John Williamson apresentou em uma reunião realizada em Washington uma síntese de 10 medidas: o ajuste estrutural do défict público, a redução do tamanho do Estado, a privatização das estatais, a abertura do comércio internacional, o fim das restrições do capital externo, a abertura financeira às instituições internacionais, a desregulamentação da economia, a reestruturação do sistema previdenciário, o investimento em infraestrutura básica e a fiscalização dos gastos públicos.

${ }^{6}$ Como a Era Vergas (1930-1945) e a reforma militar (1964-1985).
} 
A vertente social da reforma é justificada em uma variação do modelo da administração pública o chamado Public Service Oriented - PSO, que dentre suas características considera o cidadão como um sujeito não só de direito, mas também de deveres, como aquele que deve participar ativamente não só em âmbito político, mas também em âmbito administrativo de decisões coletivas (SANTOS, 2017). Este modelo defende as virtudes políticas da descentralização, diferenciando-se do modelo puramente gerencial por pensar coletivamente no indivíduo como cidadão e não como mero consumidor, aproximando-o do centro de decisões dos serviços públicos e atribuindo-lhe direitos e deveres, podendo escolher os equipamentos sociais que lhe oferecem melhor qualidade (ABRUCIO, 1997). ${ }^{7}$

Dois grandes desafios se destacaram no Brasil nos anos 1990: (a) reestruturar as relações de poder político da sociedade de forma a atender aos direitos fundamentais expostos na Constituição Federal de 1988, tendo como pano de fundo o ideal do Estado Democrático de Direito, e; (b) reorganizar o aparato burocrático-administrativo de forma a propiciar à sociedade brasileira o alinhamento neoliberal imposto por organismos internacionais e ao mesmo tempo garantir aos cidadãos os direitos sociais expressos na Nova Constituição.

Para a consecução de seus objetivos a administração gerencial se opôs à gestão burocrática de forma a retirar da atribuição do Estado aquilo que não lhe fosse essencial. Naquele momento destacava-se Luiz Carlos Bresser-Pereira - ministro do Ministério da Administração Federal e Reforma do Estado (1995-1998) - protagonizando uma série de mudanças em relação à organização administrativa estatal, como a reforma do terceiro setor, a criação de agências reguladoras e executivas, etc., centralizando a atuação do Estado naquilo que lhe fosse exclusivo e descentralizar àquilo que não lhe fosse.

Outro ponto importante, sob a perspectiva da nova administração pública, foi a inclusão do princípio da eficiência como princípio expresso na Constituição Federal, a partir da Emenda Constitucional no 19/98, para MARINELA (2013, p. 44):

A eficiência exige que a atividade administrativa seja exercida com presteza,
perfeição e rendimento funcional. Consiste na busca de resultados práticos de
produtividade, economicidade, com a consequente redução de desperdícios do
dinheiro público e rendimentos típicos da iniciativa privada, sendo que, aqui,
o lucro é do povo; quem ganha é o bem comum.

\footnotetext{
${ }^{7}$ Essa inclusão do aspecto democrático à reforma também deve ser analisada como consequência da, na época, recente promulgação da Constituição de 1988, pondo fim a mais de duas décadas de um regime militar marcado pela supressão de valores fundamentais de liberdade e dignidade da pessoa humana.
} 
A necessidade desecntralização do aparato Estatal advinha da necessidade de tornar eficiente e de especializar as diversas funções que lhe foram concebidas pela Constituição Federal de 1988, em especial incumbência do atendimento dos direitos sociais dos indivíduos. A possibilidade de se desenhar um ambiente desenvolvimentista, democrático e eficiente em um momento em que a sociedade saia de um regime militar de mais de duas décadas colocou em rediscussão as possibilidades de se instituir ferramentas que delegassem ao privado certas decisões que antes só eram de incumbência pública.

O momento atingia não só o Poder Executivo, mas também os outros Poderes. As ferramentas de redesenho político nas decisões públicas despontavam como características dos preceitos democráticos da Constituição e apesar do voto ter sido uma importante reconquista o Poder Legislativo precisou se reorganizar de forma a permitir espaços públicos de discussões como as audiências públicas - e em alguns casos percebeu até o seu poder decisional diminuído com a fixação de orçamentos participativos vinculantes ou mesmo com a necessidade de votações em Conselhos Municipais.

O monopólio da Justiça pelo Poder Judiciário também fora colocado em xeque. Não por eventual incompetência ou por falta de legitimidade, mas para fins de atingimento de uma maior eficiência, rapidez e especialidade de decisões surgidas em conflitos. Paradoxalmente o atendimento do direito constitucional do acesso à Justiça seguiu o caminho da própria "desjudicialização" com ferramentas como a criação de Justiças Especializadas (como a desportiva e os tribunais arbitrais) e o foco em prevenção de mediação de conflitos.

Os novos modelos que incluíam novas instituições na administração indireta, e as novas ferramentas que permitiam a participação do indivíduo na decisão pública foram frutos de uma nova perspectiva de rearranjo do Estado. Eram bem-vindas as ferramentas que possibilitassem ao gestor público uma possibilidade de delegar à terceiros ou particulares a resolução de problemas típicos da administração pública sem que se perdesse a característica da indisponibilidade do direito público.

Conflitos judiciais que envolvam o Estado demandam não só uma grande parcela do Judiciário, mas também do Executivo. Enquanto a lide formada exigirá todos os tramites processuais atinentes à Justiça, também demandará esforços do Executivo - que deverá, por meio de seus agentes, buscar e defender os seus direitos. Medidas alternativas de resolução de conflitos na administração pública passaram a ser uma possibilidade de flexibilização e de descentralização de decisões que, lato sensu, envolviam a discussão sobre a disponibilidade do direito público. A necessidade de rearranjo do Estado, porém, pareceu superar entendimentos 
mais ortodoxos sobre a impossibilidade de se aplicar institutos como a arbitragem à conflitos em que o Estado figurasse como parte. Assim, o atual entendimento da aplicação do instituto da arbitragem, em especial após a edição da Lei 13.129/15 parece coadunar com os fundamentos da nova administração pública, ainda que, de acordo com parte da doutrina, sua aplicabilidade pudesse impedir a defesa do princípio da indisponibilidade do direito público, conforme veremos nos próximos itens.

\section{FORMAS DE RESOLUÇÃO DE CONFLITO NA ADMINISTRAÇÃO PÚBLICA}

Estatísticas contemporâneas sobre os trabalhos do Poder Judiciário no Brasil ainda mostram que a prestação jurisdicional está muito distante do cidadão. Dentre os motivos desta distância não podemos descartar a hipótese de que Constituição 1988 se por um lado fez garantir uma série de novos direitos sociais, por outro potencializou os conflitos de toda ordem, sem que fosse possível a expansão proporcional dos aparatos administrativos e institucionais para atender tal aumento de tal demanda. Assistimos a um intenso processo de juridificação do conflito social, ou seja, todo tipo de conflito, cada vez mais, tende a assumir a forma de um processo judicial (SORJ, 2001, p.102). Essa litigiosidade mostra-se também crescente em relação ao Estado, que considerado em todas suas instâncias é o maior litigante em processos judiciais.

A discussão sobre uma justiça mais célere e uma forma mais eficiente de resolução de conflitos permeia a sociedade brasileira há tempos. Neste sentido algumas formas extrajudiciais de solução de conflitos vêm ganhando forças tanto na seara pública quanto na privada, podendo caminhar na mesma direção de reformas do próprio processo judicial ${ }^{8}$, contribuindo para uma política ainda mais abrangente de "desafogamento" do Judiciário.

Argumenta-se que uma das vantagens da busca em formas alternativas de resolução de conflitos é o retorno de um modelo de justiça mais comunitário e consensual, em oposição à distante jurisdição formal estatal. Para Boaventura de Souza Santos (1996, p.16-18) há em todas as sociedades minimamente complexas um conjunto de mecanismos de resolução de conflitos, considerando neste rol todas aquelas instâncias exteriores e diferentes das partes que tomarão o poder de decisão. Estas, para o autor “[...] variam enormemente segundo a oficialidade, a

\footnotetext{
${ }^{8}$ Pode-se exemplificar com a recente reforma do Código de Processo Civil dada pela Lei no 13.105/2015.
} 
formalidade, a acessibilidade, a especialização, a eficácia, a eficiência, a distância cultural, etc. Em geral os tribunais tendem a ocupar um dos extremos em muitas dessas dimensões.".

Este conjunto mais ou menos numeroso de mecanismos, que foi criado classicamente para as instituições privadas, pode ser utilizado pelo Estado não só na busca de atender o princípio da eficiência, mas também como uma aproximação da administração pública com a sociedade, aumentando a participação ativa dos cidadãos e agindo através de vias consensuais.

Observamos que a partir do surgimento do conflito a consensualidade pode se dar de forma interna, de uma forma em que as próprias partes envolvidas criarão métodos de resolução do problema por meio de concessões mútuas (conciliação) mesmo que assistidas ou intermediadas por um terceiro (como é o caso da mediação), ou poderá haver uma consensualidade no sentido do acordo quanto à forma de se delegar à terceiro o poder de decisão (como é o caso da arbitragem). A prática da consensualidade, na administração pública, de acordo com Medauar (2003, p.209) é um:

[...] modo de atuar encontra-se a ideia de troca de pontos de vista, a ideia de elaboração em comum de soluções, o que exige acordo entre vários sujeitos (todos públicos ou em parte públicos e em parte privados); é a substituição da decisão pela discussão, do comando pela negociação; é a Administração por consenso, contrapondo-se à Administração por autoridade. Nos países sem regime administrativo sempre foram empregados de modo amplo; nos ordenamentos de regime administrativo vêm aumentando em quantidade e qualidade.

Esta possibilidade agir da administração pública - consensual, democrática e participativa - se manifesta na forma de diferentes instrumentos de transformação social. É justamente o que entende Fernando Machado (2016, p.127) sobre os métodos alternativos de solução de conflitos quando implementados e incorporados na administração pública, como uma opção ao Judiciário, considera que sendo o Estado o maior utilizador da estrutura do Poder Judiciário, é imperiosa a instrumentalização de mecanismos hábeis a reduzir os conflitos, pois a solução de conflitos pela sua forma negociada, “[...] deverá se sobrepor à imposição estatal da sentença, pois a efetividade de democracia de um povo corresponde à medida a participação dos seus indivíduos na condução dos processos transformadores da própria sociedade.”. Observa-se assim não só vantagens objetivas - ganho de especialidade nas soluções e diminuição da demanda do Judiciário - mas também a mudança ideológica da administração pública litigante para a administração consensual, fortalecendo a democracia.

Algumas formas de resolução de conflitos têm ganhado maior atenção do legislador através da formulação de projetos legislativos específicos que o regulassem instrumentalmente. 
A partir de meados dos anos 2000 houve uma série de campanhas pela mediação e conciliação que permearam os Tribunais de Justiça brasileiros, assim como mais tarde em 2015 a reforma do Código do Processo Civil trouxe como um de seus princípios norteadores o princípio da cooperação que, somada às novas regras que tornavam ainda mais presentes as audiências de conciliação, visava atingir o direito material sem a necessidade de se estender em demasia as formalidades processuais.

Mas, mesmo com a tentativa de fortalecer a conciliação, o Judiciário ainda trazia para si as demandas. Dificilmente mecanismos alternativos eram colocados em prática quando um dos litigantes fosse algum ente público (pois demandaria uma lei específica do ente que autorizasse ao seu representante transacionar). Diferentemente é o caso da arbitragem, pois sua aplicação substitui todo o aparato estrutural do Poder Judiciário pela estrutura de um Tribunal ou Câmara Arbitral, e mais, a regulação da arbitragem foi fortalecida como um instituto particular com a Lei 9.307/96, e mais tardar teve o seu campo de aplicação ampliado com a Lei 13.129/15, que de forma mais incisiva trouxe a possibilidade geral de sua aplicação ao maior litigante na Justiça Brasileira: o Estado.

\section{ARBITRAGEM NO DIREITO BRASILEIRO: NOS LIMITES DO "INTERESSE PÚBLICO"}

As relações arbitrais estão presentes em nosso país há muito mais tempo do que se imagina: desde os tempos da colonização portuguesa, quando a maioria dos conflitos solucionados pela arbitragem eram os de respeito à Legislação Comercial. Na Constituição Imperial de 1824, temos a primeira manifestação de arbitragem em uma fonte puramente brasileira, porém ainda institucionalizada de uma forma ampla e abstrata, em seu artigo 160, que cita:

Nas civeis, e nas penaes civilmente intentadas, poderão as Partes nomear Juizes Árbitros. Suas Sentenças serão executadas sem recurso, se assim o convencionarem as mesmas Partes.”. Apesar de facultatividade, na época a arbitragem na pratica tinha um caráter coativo, até que pela Lei $n^{\circ} 1.350$ de 1866 foi revogada.

Com a proclamação da república nenhuma mudança em relação a arbitragem surgiu. Aliás, a próxima Constituição, em 1891, não trouxe dispositivos que previssem (nem que impedissem) o uso da arbitragem. Na prática, a arbitragem era praticada sem uma orientação 
legislativa vigente que a caracterizava, porém, seu uso tornou-se autorizado pelas leis, sendo consolidada no Decreto ${ }^{\circ} 3.084$, de 5 de novembro de $1898^{9}$.

Em algumas questões internacionais o Brasil também se utilizou de mecanismos arbitrais, principalmente nos conflitos que envolviam a posse e demarcação de terras como questões de fronteira com a Argentina em 1900 e com a Guiana Inglesa em 1904, ou ainda a questão do Acre, com a Bolívia em 1909. Questões marítimas com países como Grã-Bretanha, Estados Unidos e outros também, foram frequentemente em nossa história, resolvidas pela arbitragem (VALÉRIO, 2004. p.12).

No decorrer do tempo, as diversas Constituições do Brasil que seguiram (1937, 1946, 1967, 1969) silenciaram acerca do instituto da arbitragem, mas concomitantemente, não impediram que legislações infraconstitucionais como Código Civil prosperasse acerca do assunto nos anos de 1916 (arts.1037 a 1.048) e mais tarde os Códigos de Processo Civil de 1939 $(\operatorname{arts} .1031 \text { a 1046) e de } 1973 \text { (arts. } 1.072 \text { a 1.102) })^{10}$.

A partir da década de 1990 já era visível por parte dos legisladores uma tendência de modernização do instituto da arbitragem no ordenamento jurídico brasileiro, caminhando sobre as mesmas justificativas de rearranjo do aparato Estatal e da necessidade de modernização da administração pública, como já aprofundamos anteriormente.

Tentativas foram feitas, originando três anteprojetos de lei, incialmente sem nenhum êxito. Até que em 1992, o Projeto de Lei 78/92, foi apresentado ao Congresso Nacional pelo vice-presidente da República Marco Maciel e após aprovação do projeto com sua emenda o mesmo foi encaminhado para o autógrafo legislativo que sancionou a Lei 9307/96 em sessão solene no dia 23 de setembro de 1996, lei esta que viria a se fortificar em seus mais de vinte anos de vigência, até ser modificada recentemente, em uma tentativa de ampliação de sua abrangência.

\subsection{Lei $9.307 / 96$}

A Lei de Arbitragem, teve como fontes inspiradoras pesquisas, convenções e seminários realizados durante os anos que a antecederam, como a pesquisa conjunta realizada pelo Instituto

\footnotetext{
${ }^{9}$ O Decreto 3.084 de 1898 tratava da arbitragem em seu Título IX e era disposto em um rol de 71 artigos.

${ }^{10}$ O Código Civil de 1.916 tratou da arbitragem como "compromisso" no Capitulo X, mais especificamente como parte do Direito Obrigacional, de cunho essencialmente privado. Já o Código Civil de 2002 o rol de artigos que tratavam da arbitragem diminuiu consideravelmente, mas de forma abrangente o Código trouxe o artigo 853 também dentro do Título de Direito Obrigacional - uma previsão mais ampla sobre o instituto, agora que regrado em Lei específica - 9307 de 1996.
} 
Liberal de Pernambuco - ILP e pela Associação dos Advogados de Empresa de Pernambuco AAEP denominada Operação Arbiter, ou ainda o Seminário Nacional sobre Arbitragem realizado em Curitiba - PR, no ano de 1991, sendo neste mesmo ano foi constituída uma comissão relatora para que esta criasse um anteprojeto de lei acerca da arbitragem que acabou sendo enviado em 1992 ao ex vice-presidente da República, então senador Marcos Maciel. Segundo Marco Aurélio Gumieri Valério (2004), este projeto sofreu algumas modificações durante sua tramitação que não alterou de certa forma seu conteúdo substancial, e que assim, anos mais tarde, originou a Lei n. 9.307/96 e 23 de setembro daquele ano passou a vigorar a partir do final do período de vacatio legis. Dentre suas finalidades estaria a de suprir a demanda do Judiciário, resolvendo de forma rápida os litígios que contribuíam para a morosidade da Justiça brasileira.

Após a sua homologação a lei da arbitragem abriu as portas para que surgissem comitês, conselhos e, principalmente, as câmaras arbitrais especializadas em solução de conflitos, tomando de certa forma a responsabilidade da solução de conflitos particulares, que pela morosidade do sistema judiciário brasileiro, acabou despontando como uma alternativa viável para os contratos particulares em geral.

A Lei 9.307/96 prevê em seu artigo $1^{\circ}$ a necessidade da disponibilidade do direito para que este seja objeto do procedimento arbitral, esta disposição se dá pelo próprio instituto arbitral estar intimamente ligado ao princípio da autonomia da vontade (BOSCO LEE, 2001, p.21), o que de certa forma colidiria com o âmbito da esfera pública na qual os direitos são predominantemente indisponíveis, assim como a inerente autonomia da vontade das formas de resolução de conflito alternativas estariam suprimidas diretamente pelos princípios da legalidade e da indisponibilidade, e indiretamente pela supremacia do direito público, limitando o administrador público na escolha de utilizar-se de formas alternativas de parte de seus conflitos.

Essa disponibilidade de direitos, a grosso modo, estaria suprimida quando a relação envolvesse o Estado, quando a natureza do litigio fosse de ordem pública, frente ao princípio da legalidade, mas não haveria qualquer oposição quando o Estado estivesse atuando em atos de natureza privada, ocasião em que se equipara aos particulares (CARMONA, 2009, p.45).

Já para Fernando Machado (2016, p.109) a autocomposição tem sido gradativamente inserida no ordenamento jurídico brasileiro permitindo a "[...] prevenção ou o encerramento de litígios [...] entre a administração pública e potenciais infratores, que invariavelmente culminam na disposição de direitos marginais ao núcleo intangível dos direitos indisponíveis." Para o 
autor, a disponibilidade do direitos atingiria um campo maior do que somente às relações privadas, pois a interpretação à ser dada às hipóteses de arbitragem se assemelhariam à cautela dispensada aos direitos difusos e coletivos, desde que se garantissem efetivos meios de fiscalização do conteúdo material dos termos acordados (MACHADO, p.109).

Dentre as discussões que permeiam a esfera pública, não só a conceituação de "direito patrimonial disponível", mas também os limites da "(in)disponibilidade da administração pública" são temas tormentosos e historicamente debatidos na doutrina. A visão clássica do Direito Administrativo, por outro lado, conceituaria o agir do Estado como pertencente a coletividade, baseada em um eixo condutor preso ao princípio não só da supremacia do direito público, mas também preso à legalidade (NOGUEIRA, p. 3-6). Neste sentido o agir do gestor público só se pautaria e estaria autorizado se presente em lei.

Assim, após a promulgação da Lei 9.307/96, percebe-se que uma série de leis que se voltam à administração pública para suprimir os questionamentos teóricos, passaram a autorizar a utilização da arbitragem de forma expressa, como por exemplo a Lei 9.472/97 (Lei que criou a ANATEL) ${ }^{11}$, a Lei 9.478 (que dispõe sobre a matriz energética e cria a ANP) ${ }^{12}$, a Lei 10.233/01 (que dispõe sobre a reestruturação dos transportes aquaviário e terrestre) ${ }^{13}$, a Lei 11.079/04 (que dispõe sobre normas gerais de contratação de PPPs no âmbito da administração pública $)^{14}$ entre outras.

O entendimento de que alguma liberdade de transação somente se daria por meio de autorização expressa específica trazia ao administrador público uma insegurança negociação que fosse alternativa à forma judicial de resolução de conflito, e, fora no âmbito da União - ente de maior estruturação - e das hipóteses previstas em lei, a arbitragem na administração pública caiu, de certa forma, em desuso.

A análise do ordenamento jurídico brasileiro relativo à arbitragem após a Lei 9307/96, e antes de sua reforma pela Lei 13.129/15, refletia uma discussão sobre duas possibilidades da interpretação de seu uso pela administração pública: (a) ou se permitia a utilização da

\footnotetext{
${ }^{11}$ Prevê em seu artigo 93, XV, que "(...)o contrato de concessão indicará o foro e o modo para solução extrajudicial das divergências contratuais."

12 Prevê como cláusula essencial dos contratos de concessão "as regras sobre solução de controvérsias, relacionadas com o contrato e sua execução, inclusive a conciliação e a arbitragem internacional", em seu artigo 43, X.

13 Prevê como cláusula essencial dos contratos de concessão "as regras sobre solução de controvérsias, relacionadas com o contrato e sua execução, inclusive a conciliação e a arbitragem internacional", em seu artigo 35 , XVI.

${ }^{14} \mathrm{O}$ artigo 11 permite o "emprego dos mecanismos privados de resolução de disputas, inclusive a arbitragem, a ser realizada no Brasil e em língua portuguesa, nos termos da Lei no 9.307, de 23 de setembro de 1996, para dirimir conflitos decorrentes ou relacionados ao contrato."
} 
arbitragem para todos aqueles direitos que não fossem explicitamente indisponíveis ou que não traziam a expressa proibição de transação em lei; (b) ou se permitia o seu uso apenas para aquelas relações que fossem explicitamente privadas ou em situações em que o seu uso fosse autorizado por lei.

Parece lógico pensar que em razão da insegurança jurídica a decisão do agente público na maioria das vezes seria a de levar o conflito ao Judiciário. Tal fato provavelmente contribuiu para a manutenção do Estado como o maior litigante da Justiça brasileira, conforme tabela retirada do Relatório do $\mathrm{CNJ}, 2011^{15}$ :

Tabela 1 - Listagem dos 10 maiores litigantes contendo o percentual de processos em relação aos 100 maiores litigantes da Justiça.

\begin{tabular}{|c|c|c|c|c|c|c|c|c|}
\hline \multirow{3}{*}{$\frac{\text { Rank }}{1}$} & \multicolumn{8}{|c|}{ Cem Maiores Litigantes } \\
\hline & \multicolumn{2}{|l|}{ Nacional } & \multicolumn{2}{|l|}{ Justica Federal } & \multicolumn{2}{|l|}{ Justica do Trabalho } & \multicolumn{2}{|l|}{ Justiça Estadual } \\
\hline & $\begin{array}{l}\text { INSS - INSTITUTO } \\
\text { NACIONAL DO SEGURO } \\
\text { SOCIAL }\end{array}$ & $22.33 \%$ & $\begin{array}{l}\text { NSS - INSTITUTO } \\
\text { NACIONAL DO SEGURO } \\
\text { SOCWL }\end{array}$ & $43.12 \%$ & UNALO & $16.73 \%$ & $\begin{array}{l}\text { ESTADO DO RIO GRANDE } \\
\text { DO SUL }\end{array}$ & $7,73 x$ \\
\hline 2 & $\begin{array}{l}\text { CEF - CALXA ECONOMICA } \\
\text { FEDERAL }\end{array}$ & $8,50 \%$ & $\begin{array}{l}\text { CEF - CALXA ECONOMICA } \\
\text { FEDERAL }\end{array}$ & $18,24 \%$ & $\begin{array}{l}\text { INSS - ENSTITUTO NACIONAL DO } \\
\text { SEGURO SOCIAL }\end{array}$ & $6,41 \%$ & BANCO DO BRASIL SIA. & $7,12 \%$ \\
\hline 3 & FAZENDA NACIONAL & $7,45 \%$ & FAZENDA NACIONAL. & $15,65 \%$ & CEF - CADXA ECONOMICA FEDERAL & $5,29 \%$ & BANCO BRADESCO SIA & $6,70 \%$ \\
\hline 4 & UNIAOO & $6,97 \%$ & UNIAO & $12,77 \%$ & $\begin{array}{l}\text { GRUPO CEEE - COMPANHIA } \\
\text { ESTADUAL DE ENERGLA ELETRICA }\end{array}$ & $5.22 \%$ & $\begin{array}{l}\text { INSS - INSTITUTO } \\
\text { NACIONAL DO SEGURO } \\
\text { SOCIAL. }\end{array}$ & $5.25 x$ \\
\hline 5 & BANCO DO BRASIL SIA. & $4.24 \%$ & $\begin{array}{l}\text { AOVOCACLA GERAL DA } \\
\text { UNLAO }\end{array}$ & $1,75 \%$ & BANCO DO BRASIL SUA. & $4,82 \%$ & BANCO ITAÜ SIA & $5.92 \%$ \\
\hline 6 & $\begin{array}{l}\text { ESTADO DO RIO GRANDE } \\
\text { DO SUL. }\end{array}$ & $4,24 \%$ & $\begin{array}{l}\text { FUNASA - FUNDACAOAO } \\
\text { NACIONAL DE SAUDE }\end{array}$ & $0.79 \%$ & TELEMAR SIA & $4.31 \%$ & $\begin{array}{l}\text { BRASIL TELECOM } \\
\text { CELULAR SIA }\end{array}$ & $5.77 x$ \\
\hline 7 & BANCO BRADESCO SIA & $3,84 \%$ & $\begin{array}{l}\text { INCAA-INSTITUTO } \\
\text { NACIONLL DE } \\
\text { COLONIZACLO E REFORMA } \\
\text { AGRARIA }\end{array}$ & $0,48 \%$ & $\begin{array}{l}\text { PETROBRAS - PETROLEO } \\
\text { BRASILEIRO SIA. }\end{array}$ & $3,80 \%$ & BANCO FINASA SIA & $4,08 \%$ \\
\hline 8 & BANCO ITAÜ SIA & $3,43 \%$ & $\begin{array}{l}\text { EMGEA - EMPRESA } \\
\text { GESTORA DE ATIVOS }\end{array}$ & $0,47 \%$ & FAZENDA NACIONAL & $3,29 \%$ & MUNICIPIO DE MANAUS & $3.81 \%$ \\
\hline 9 & $\begin{array}{l}\text { BRASIL TELECOM } \\
\text { CELULAR SIA }\end{array}$ & $3.28 \%$ & $\begin{array}{l}\text { BAAMA-INSTITUTO } \\
\text { BRASILEIRO DO MEIO } \\
\text { AMEGENTE E DOS } \\
\text { RECURSOS NATURAIS } \\
\text { RENOVAVEIS } \\
\end{array}$ & $0.47 \%$ & BANCO ITAÓ SIA & $2,89 \%$ & MUNICIPIO DE GOUANIA & $3,76 \%$ \\
\hline 10 & BANCO FINASA S/A & $2,19 \%$ & $\begin{array}{l}\text { BACEN - BANCO CENTRAL } \\
\text { DO BRASIL. }\end{array}$ & $0,39 \%$ & BANCO BRADESCO SIA & $2,81 \%$ & $\begin{array}{l}\text { BANCO SANTANDER } \\
\text { BRASIL SIA }\end{array}$ & $3.14 \%$ \\
\hline
\end{tabular}

Fonte: Conselho Nacional de Justiça (2012)

No ano de 2011 tanto na Justiça Federal quanto na Estadual e na Justiça do Trabalho, o maior litigante é pessoa jurídica de direito público. Notadamente, as primeiras 10 posições em cada tribunal figuram predominantemente pessoas da administração pública direta ou indireta. Sendo o próprio Estado o fomentador do poder judiciário e seus tribunais, e ele mesmo sendo o maior litigante em todas as esferas deste sistema atualmente sobrecarregado, é lógica a necessidade da busca por alternativas.

Assim, como se não fosse somente crescente o número de leis que previam expressamente a possibilidade do uso da arbitragem, a doutrina e a jurisprudência também

\footnotetext{
${ }^{15}$ Foi escolhido um ano intermediário entre a Lei 9.307/96 e a Lei 13.129/15. O ano de 2011 parece oportuno para a compreensão da situação descrita nos parágrafos anteriores.
} 
passaram a se posicionar no sentido de sua admissão cada vez maior em casos que envolvam o poder público. Ao julgar o Recurso Especial no 904.813/PR, o Superior Tribunal de Justiça anotou que:

Tanto a doutrina como a jurisprudência já sinalizaram no sentido de que não existe óbice na estipulação da arbitragem pelo poder público, notadamente pelas sociedades de economia mista, admitindo como válidas as cláusulas compromissórias previstas em editais convocatórios de licitação e contratos". E, ainda segundo se registrou em tal julgado, "o fato de não haver previsão da arbitragem no edital de licitação ou no contrato celebrado entre as partes não invalida o compromisso arbitral firmado posteriormente ${ }^{16}$

Em vista de fortalecimento da aplicação do instituto, principalmente quanto a sua permissividade geral, por fim, o PL nº406/13 do Senado Federal, foi posto em votação, restando na promulgação da Lei 13.129/15 que trouxe a previsão expressa e geral da possibilidade da utilização da arbitragem pela administração pública.

\section{2 - Lei 13.129/15}

Em 27 de maio de 2015 foi publicada a Lei 13.129/15, que, dentre outros dispositivos, incluiu no artigo $1^{\circ}$ da Lei $9.307 / 96$ a previsão geral de possibilidade de uso da arbitragem pela administração pública ao trazer expressamente que a "[...] administração pública direta e indireta poderá utilizar-se da arbitragem para dirimir conflitos relativos a direitos patrimoniais disponíveis.". Em suma, finalmente houve uma autorização geral para a utilização da arbitragem pela administração, mas com o caráter facultativo - na sua interpretação literal, em razão do termo "poderá", escolhido pelo legislador. Vejamos que a autorização para utilização da arbitragem pela administração pública se limita expressamente em relação aos direitos patrimoniais disponíveis, mantendo a incerteza sobre a extensão dessa expressão.

Importante ressaltar que tal dispositivo não se trata de uma inovação jurídica: leis locais, municipais e estaduais, como a Lei 19.477/2011 do Estado de Minas Gerais - chamada "Lei Mineira da Arbitragem" - já previam a possibilidade de utilização da arbitragem pela administração pública expressamente, por exemplo, a lei mineira prevê em seu artigo $2^{\text {o17 }}$ a possibilidade do governo estadual de Minas Gerais utilizar o instituto como forma alternativa

\footnotetext{
16 (STJ, $3^{\mathrm{a}}$ T., REsp 904.813/PR, rel. Min. Nancy Andrighi, j. 20/10/2011, DJe 28/2/2012)

17 Art. $2^{\circ}$.O Estado e os órgãos e as entidades das administrações estaduais direta e indireta poderão optar pela adoção do juízo arbitral para a solução dos conflitos relativos a direito patrimonial disponível.
} 
de resolução de conflitos de maneira ampla e não ligada a objetos específicos, desde que o direito em conflito seja patrimonial disponível. Também já eram existentes em âmbito federal as autorizações para utilização da arbitragem em searas específicas - como nas já citadas lei de criação de agências reguladoras, lei da PPPs, etc.

Positivou-se genericamente a possibilidade de utilização da arbitragem pela administração pública para todo e qualquer conflito que envolva direitos patrimoniais disponíveis em qualquer ente federativo, mas ao mesmo tempo imposições também se tornaram expressas, como a determinação de que a arbitragem, quando utilizada pela administração pública, não poderá ser por equidade ${ }^{18}$, devendo sempre ser feita com base nas regras de direito - tal imposição é fruto do princípio da legalidade (art. 37, da CF/88) a fim de evitar questionamentos quanto à sua constitucionalidade.

Ganha força a interpretação de que não é uma limitação para o uso da arbitragem o fato de o litigante ser pessoa jurídica de direito público, mas sim, qual seria a medida da disponibilidade do objeto que se litiga. Para fins de uma interpretação literal a disponibilidade do direito é o fator preponderante para a utilização da arbitragem, mesmo que pelo poder público. Ocorre que o citado art. $2^{\circ}$ optou por não especificar o que considera direito disponível, cabendo ainda àquele quem o interpreta definir as balizas que limitariam o que é ou não, e esta interpretação, quando envolve a administração pública, retoma a imprescindível análise do que seria o "interesse público".

A Lei 13.129/15 também traz expressamente o princípio da publicidade como extremamente necessário quando da utilização do procedimento arbitral na esfera pública ${ }^{19}$. Tal exigência de publicidade evidencia a essencialidade dos princípios da administração pública contidos no artigo 37 da Constituição Federal, assim como reflete a supremacia do interesse público sobre o privado pois mesmo que o instituto da arbitragem naturalmente traga um procedimento que é, como regra, sigiloso. Discute-se novamente a disponibilidade, agora quanto ao princípio da publicidade na administração pública, nos casos em que a administração pública opta por realizar o procedimento arbitral.

Carlos Alberto Carmona (2009, p. 51-52), anteriormente à Lei 13.129/15, já entendia que a solução do conflito da publicidade dos atos da administração pública com a característica

\footnotetext{
${ }^{18}$ A arbitragem por equidade está prevista no artigo $2^{\circ}$ da Lei $9.306 / 97$, significando a possibilidade de as partes decidirem por equidade. Para Alípio Silveira (, a equidade está intimamente relacionada com a noção de justiça, como ideia ou princípio e, com fundamento, na melhor doutrina, ensina que fazer uso da equidade não significa julgar contra a lei, mas sim atenuar a dureza da lei

${ }^{19}$ A Lei incluiu o seguinte parágrafo ao artigo $2^{\circ}$ da Lei 9.306/97: $§ 3^{\circ}$ A arbitragem que envolva a administração pública será sempre de direito e respeitará o princípio da publicidade.”
} 
sigilosa da arbitragem estaria no meio termo ao "[...] dar acesso aos interessados à decisão e aos atos essenciais do processo arbitral (quando necessário), preservando-se, porém, o sigilo dos debates e a confidencialidade dos documentos que instruíram o processo arbitral.”.

Parece inquestionável a necessária observância do princípio da publicidade à administração pública utilizar-se da arbitragem seja em razão principiológica, por constar expressamente no artigo 37 da Constituição Federal, seja em razão de sua expressa previsão na Lei 13.129/15, que lhe deu ainda maior ênfase. Observa-se, porém, que sua previsão na lei específica não traz mitigações ou aplicações em casos restritos, o que nos levaria a entender, que sua aplicabilidade é ilimitada em relação ao procedimento arbitral, raciocínio levado à tona ao contrastar a lei de arbitragem com o princípio da publicidade do artigo 37 , caput, da Constituição Federal e com normas vigentes e específicas sobre o dever de sigilo da administração pública, como é o caso do artigo $3^{\circ}$ da recente Lei de Acesso à Informação (LAI) - que é clara a tratar a "publicidade como preceito geral e o sigilo como exceção "20.

O legislador não trouxe na Lei 13.129/15 quais seriam, especificadamente, as situações do procedimento arbitral que pudessem ser interpretados como exceções ao princípio da publicidade, o que nos leva a entender à inafastabilidade das normas dispostas na LAI e, é claro na imperatividade da Constituição Federal ${ }^{21}$.

A Lei $13.129 / 15$ ainda incluiu o parágrafo $2^{\circ}$ no artigo $1^{\circ}$ da lei de arbitragem, expressamente prevendo que a "autoridade ou órgão competente da administração pública direta para a celebração de convenção de arbitragem é a mesma para a realização de acordos ou transações", ou seja, acaba por atribuir à opção da arbitragem ao mesmo agente que tenha poderes para transacionar direito. Ocorre que, seria "[...] irrazoável atribuir a todas as autoridades competentes para firmar contratos o poder de decidir sobre a submissão, do juízo arbitral, dos litígios envolvendo a administração pública." (DI PIETRO, 2015), e ainda, na esfera administrativa não há um dispositivo geral que preveja de quem é a autoridade para a realização da transação, ficando tal matéria restrita a lei de cada ente - e inexistente na grande maioria deles.

\footnotetext{
${ }^{20}$ Art. $3^{\circ}$, I: observância da publicidade como preceito geral e do sigilo como exceção;

${ }^{21}$ Art. $5^{\circ}$, XXXIII - todos têm direito a receber dos órgãos públicos informações de seu interesse particular, ou de interesse coletivo ou geral, que serão prestadas no prazo da lei, sob pena de responsabilidade, ressalvadas aquelas cujo sigilo seja imprescindível à segurança da sociedade e do Estado.
} 


\section{CONSIDERAÇÕES FINAIS}

A lei da arbitragem, muito embora possa ser vista como um instrumento voltado à atividade privada, pouco a pouco vêm ganhando espaço em legislativo com a finalidade de reger relações que envolvam o direito público. Essa intensificação vai ao encontro dos preceitos do consensualismo na administração pública e instrumentaliza uma relação entre administração entre Estado e sociedade de uma forma horizontalizada, buscando concretizar o princípio da eficiência da administração pública.

Apesar do fortalecimento da institucionalização da arbitragem, de forma geral no Brasil, principalmente após a vigência da Lei 9.306/97, este instituto não foi capaz de incorporá-la de forma segura no dia a dia da administração pública. E, embora a doutrina e a jurisprudência, em sua maioria, já entendessem que a arbitragem envolvendo o Estado estivesse amplamente autorizada, mesmo em respeito aos princípios que sobre eles se aplicam, ainda se encontrava resistência por parte de alguns setores.

Mostrou-se visível o movimento de consensualização da administração pública a partir da década de 90, e mesmo sendo o Estado historicamente o maior demandante de ações judiciárias, até a promulgação das modificações propostas pela Lei 13.129/2015 as previsões da aplicação Lei de Arbitragem no direito público encontravam grande resistência por parte do pensamento do direito administrativo clássico. Após as modificações implementadas pela Lei 13.129/15, prevendo expressamente, ainda que de forma genérica, a possibilidade de a administração pública direta e indireta valer-se da arbitragem para todo e qualquer conflito que envolva direitos patrimoniais disponíveis, fortaleceu-se o entendimento pela possibilidade da utilização deste instituto para tal fim.

Muito embora expressa a possibilidade da utilização da arbitragem como um dos meios alternativos de solução de controversas pelo Estado, não foram previstos quais seriam os chamados direitos patrimoniais disponíveis assim como também há ausência de previsão de quais seriam agentes públicos competentes para dispor dos objetos da lide arbitrada, deixando tal trabalho para a legislação local, doutrina, e análise jurisprudencial in casu. Estabelecer o que pode ser disponível pelo agente público é uma das facetas do próprio estudo daquilo que se denomina como interesse público, e, mais do que isso, é discutir qual seria essa parcela e quem é o seu legitimado para dispô-lo.

A Lei 13.129/25 mostra-se, portanto, como uma importante alteração legislativa que visa o fortalecimento do consensualismo e da busca por meios alternativos em prol da solução 
de problemas da administração pública, mas ainda insuficiente para a regulação por completo da aplicação da arbitragem na esfera pública, necessitando da interpretação de outros institutos, pois a sua aplicabilidade necessita da análise conjunta de outros princípios e normas que lidam diretamente com aquilo que podemos chamar de interesse público.

\section{REFERÊNCIAS LEGISLATIVAS}

BRASIL. Constituição (1988). Constituição da República Federativa do Brasil. Brasília, DF: Senado Federal. Disponível em http://www.planalto.gov.br/ccivil_03/constituicao/constituicao.htm> Acesso em 21 de julho de 2018.

BRASIL. Lei $\mathrm{n}^{\circ} 3.071$, de $1^{\circ}$ de janeiro de 1916. Código Civil dos Estados Unidos do Brasil. Diário Oficial da União, 5 de janeiro de 1916. Disponível em < http://www.planalto.gov.br/Ccivil_03/leis/L3071.htm > Acesso em 19 de julho de 2018.

BRASIL. Lei n ${ }^{\circ}$ 5.869, de 11 de janeiro de 1973. Institui o Código de Processo Civil. Diário Oficial da União, 27 de julho de 2006. Disponível em < http://www.planalto.gov.br/ccivil_03/Leis/L5869.htm >. Acesso em 19 de julho de 2018.

BRASIL. Lei n ${ }^{\circ}$ 9.307, de 23 de setembro de 1996. Dispõe sobre a arbitragem. Diário Oficial da União, 24 de setembro de 1996. Disponível em: < http://www.planalto.gov.br/ccivil_03/Leis/L9307.htm>. Acesso em 20 de julho de 2018.

BRASIL. Lei 9.472, de 16 de julho de 1997. Dispõe sobre a organização dos serviços de telecomunicações, a criação e funcionamento de um órgão regulador e outros aspectos institucionais, nos termos da Emenda Constitucional $n^{\circ}$ 8, de 1995.Diário Oficial da União, 17 de julho de 1997. Disponível em < http://www.planalto.gov.br/Ccivil_03/leis/L9472.htm>

BRASIL. Lei 9.478, de 6 de agosto de 1997. Dispõe sobre obre a política energética nacional, as atividades relativas ao monopólio do petróleo, institui o Conselho Nacional de Política Energética e a Agência Nacional do Petróleo e dá outras providências. Diário Oficial da União, 07 de agosto de 1997. Disponível em < http://www.planalto.gov.br/ccivil_03/LEIS/L9478.htm $>$ Acesso em 21 de julho de 2018.

BRASIL, Lei $\mathrm{n}^{\circ} 10.233$, de 5 de junho de 2001. Dispõe sobre a reestruturação dos transportes aquaviário e terrestre, cria o Conselho Nacional de Integração de Políticas de Transporte, a Agência Nacional de Transportes Terrestres, a Agência Nacional de Transportes Aquaviários e o Departamento Nacional de Infraestrutura de Transportes, e dá outras providências. Diário Oficial da União, 06 de junho de 2001. Disponível em < http://www.planalto.gov.br/ccivil_03/leis/LEIS_2001/L10233.htm > Acesso em 22 de julho de 2018.

BRASIL, Lei $n^{\circ} 11.079$, de 30 de dezembro de 2004. Institui normas gerais para licitação e contratação de parceria público-privada no âmbito da administração pública. Disponível em < http://www.planalto.gov.br/ccivil_03/_ato2004-2006/2004/lei/111079.htm >. Acesso em 23 de julho de 2018.

Rev. de Formas Consensuais de Solução De Conflitos | e-ISSN: 2525-9679 | Porto Alegre | v. 4 | n. 2 | p. 28 - 48 | Jul/Dez. 2018 
BRASIL. Lei $\mathrm{n}^{\circ} 13.129$, de 26 de maio de 2015. Altera a Lei $\mathrm{n}^{0}$ 9.307, de 23 de setembro de 1996, e a Lei $n^{0}$ 6.404, de 15 de dezembro de 1976. Diário Oficial da União, 27 de maio de 2015. Disponível em < http://www.planalto.gov.br/ccivil_03/_ato20152018/2015/lei/113129.htm> Acesso em 20 de julho de 2018.

MINAS GERAIS. Lei ${ }^{\circ}$ 19.477, de 12 de janeiro de 2011. Dispõe sobre a adoção do juízo arbitral para a solução de litígio em que o Estado seja parte e dá outras providências. Diário Oficial do Estado de Minas Gerais. Disponível em < https://www.almg.gov.br/consulte/legislacao/completa/completa.html?tipo=LEI\&num=19477 $\&$ ano=2011 > Acesso em 24 de julho de 2018 .

\section{Referências Bibliográficas}

ABRUCIO, Fernando Luiz. O impacto do modelo gerencial na administração pública: um breve estudo sobre a experiência internacional recente. 1997. 52 p. (Cadernos ENAP; n. 10). Disponível em < http://antigo.enap.gov.br/downloads/ec43ea4fAbrciocad\%2010.pdf > . Acesso em 15 de julho de 2018.

BOBBIO, Norberto. Estado, Governo e Sociedade: para uma teoria geral da política. Rio de Janeiro: Paz e Terra. 1987.

BOSCO LEE, João e VALENÇA FILHO, Flávio de Melo. A arbitragem no Brasil. $1^{\text {a }}$ ed., Programa CACB-BID de fortalecimento da arbitragem e da mediação comercial no Brasil. Brasília: 2001.

CARMONA, Carlos Alberto. Arbitragem e Processo, São Paulo, 3Ed. 2009.

CARVALHO FILHO, José dos Santos. Manual de Direito Administrativo. 27. ed. Atlas. São Paulo. 2014.

CONSELHO NACIONAL DE JUSTIÇA: 100 maiores litigantes. 2012. Disponível em: < http://www.revistas.unifacs.br/index.php/redu/article/viewFile/1453/1136 >

DI PIETRO, Maria Sylvia Zanella. Direito Administrativo. Editora Atlas. São Paulo, 2017.

DI PIETRO, Maria Sylvia Zanella. As possibilidades de arbitragem em contratos administrativos. Disponível em <http://www.conjur.com.br/2015-set-24/interesse-publicopossibilidades-arbitragem-contratos-administrativos2>. Acesso em 18 de julho de 2018.

MACHADO, Fernando. Indisponibilidade do interesse público: reflexos do novo CPC para resolução consensual dos conflitos. Curitiba: Juruá, 2016.

MARINELA, Fernanda. Direito Administrativo. $7^{\mathrm{a}}$ ed. Niterói: Editora Impetus, 2013, p. 44.

MEDAUAR. Odete. O Direito Administrativo em Evolução. $2^{\mathrm{a}}$ Ed. Revista dos Tribunais: São Paulo, 2003.

NOGUEIRA, Erico Ferrari. A arbitragem e sua utilização na administração pública. Disponível em < www.agu.gov.br/page/download/index/id/692918>. 
PAUlA, Ana Paula Paes de. Por uma Nova Gestão Pública; limites e potencialidades da experiência contemporânea. Rio de Janeiro: Editora FGV, 2014.

PEREIRA, Ana Lúcia Pretto; GIOVANNI, Ana Elisa Pretto Pereira. Arbitragem na Administração Pública e Indisponibilidade do Direito Público. Revista Quaestio Iuris. vol.10, $\mathrm{n}^{\circ}$. 02, Rio de Janeiro, 2017. pp. 1146-1161.

SANTOS, Anderson Ferreira dos. Evolução dos Modelos de Administração Pública no Brasil. Revista Científica Multidisciplinar Núcleo do Conhecimento. Edição 04. Ano 02, Vol. 01. pp 848-857, julho de 2017.

SANTOS, Boaventura de Sousa. Os Tribunais nas Sociedades Contemporâneas. Revista Brasileira de Ciências Sociais. V.11.n³0. São Paulo. Fev. 1996. Disponível em < http://www.anpocs.org.br/portal/publicacoes/rbcs_00_30/rbcs30_07.htm> Acesso em 13/11/2015.

SORJ, Bernardo. A nova sociedade brasileira. Rio de Janeiro. Jorge Zahar, 2001.

SOUZA, Luciene Moessa de. Meios consensuais de solução de conflitos envolvendo entes públicos: negociação, mediação e conciliação na esfera administrativa e judicial. Belo Horizonte: Fórum, 2012.

SUPERIOR TRIBUNAL DE JUSTIÇA. Recurso Especial nº 904.813/PR. Relatora: Ministra Nancy Andrigh. DJ: 28 de fevereiro de 2012.

VALÉRIO, Marco Aurélio Gumieri. Arbitragem no Direito Brasileiro, Lv. e Ed. Universitária de Direito, São Paulo, 2004. 